\title{
Recognition of Alzheimer paired helical filaments by monoclonal neurofilament antibodies is due to crossreaction with tau protein
}

(Alzheimer disease/neurofibrillary tangles/microtubule-associated proteins/phosphorylation)

\author{
Nobuyuki Nukina*, Kenneth S. Kosik, and Dennis J. Selkoe \\ Harvard Medical School and Center for Neurologic Diseases, Department of Medicine (Neurology), Brigham and Women's Hospital, 75 Francis Street,
} Boston, MA 02115

Communicated by Walle J. H. Nauta, January 12, 1987

\begin{abstract}
Neurofibrillary tangles and senile plaques are the principal pathological features of Alzheimer disease. Neurofibrillary tangles and the neurites of senile plaques contain paired helical filaments (PHF) that consist of two 10-nm filaments twisted into a double helix. The precursor proteins of PHF are not fully known. To identify these precursors, numerous immunochemical studies have been carried out during the past decade. Two apparently conflicting results have been reported. (i) Some, but not all, monoclonal antibodies to neurofilaments stained neurofibrillary tangles. (ii) Polyclonal antibodies prepared to PHF purified in $\mathrm{NaDodSO}_{4}$ because of their unusual insolubility did not recognize normal proteins, including neurofilaments, on electrophoretic transfer blots of human brain homogenates. These results have been confirmed in several laboratories, including by the use of electron microscopic labeling. Recently, we reported that polyclonal PHF antibodies include antibodies to tau proteins, a family of heat-stable microtubule-associated phosphoproteins, and that antibodies to tau stain Alzheimer neurofibrillary tangles. Those monoclonal neurofilament antibodies that recognize tangles are reported to be directed against phosphorylated epitopes. These facts prompted us to reexamine certain neurofilament monoclonal antibodies that stain neurofibrillary tangles. All monoclonal neurofilament antibodies that stain tangles that we examined, including those initially reported, reacted with tau proteins. Our results suggest that these antibodies react with phosphorylated tau proteins in PHF, not neurofilament proteins, highlighting the problem of using antibodies to phosphorylated protein epitopes in immunochemical studies. Independent evidence for the presence of neurofilament proteins in human paired helical filaments is now required.
\end{abstract}

One of the major neuropathological changes occurring in human neurons during aging and in Alzheimer disease is the neurofibrillary tangle. Tangles are made of masses of paired helical filaments (PHF), each member of which has a diameter of about $10 \mathrm{~nm}$ (1). The dystrophic cortical neurites comprising senile plaques in Alzheimer disease and human brain aging also contain PHF. The precursor proteins of PHF have been searched for intensively using immunocytochemical methods. These studies have produced three principal findings. (i) Tangles are stained by polyclonal antibodies to microtubule fractions $(2,3)$ and by polyclonal and monoclonal antibodies to microtubule-associated protein 2 (MAP2) (4, 5). (ii) Antibodies to neurofilament proteins, particularly the $M_{\mathrm{r}} 200,000$ and $M_{\mathrm{r}} 160,000$ components, stain tangles (6-9). (iii) Antibodies to partially purified PHF fractions extracted in $\mathrm{NaDodSO}_{4}$ react with no specific proteins in human brain homogenates, including neurofilament proteins, and produce a peculiar smear of immunoreactivity on electrophoretic transfer blots of Alzheimer disease brain homogenates (10).

The publication costs of this article were defrayed in part by page charge payment. This article must therefore be hereby marked "advertisement" in accordance with 18 U.S.C. $\$ 1734$ solely to indicate this fact.
However, it has been found that all of several antisera to PHF include antibodies to the MAPs designated tau when MAP fractions highly enriched in tau are examined (11-13). These antibodies to PHF include antibodies specifically directed at the phosphorylated forms of tau (14). Furthermore, a monoclonal tau antibody, Tau-1, stains tangles, and the number of tangles it recognizes is markedly increased by dephosphorylation of brain sections $(15,16)$. The monoclonal neurofilament antibodies that recognize tangles are also reported to be against phosphorylated epitopes $(17,18)$. These results prompted us to recharacterize certain monoclonal neurofilament antibodies previously shown to recognize tangles.

\section{MATERIALS AND METHODS}

Biochemical reagents, Escherichia coli alkaline phosphatase (types III-N and III-R), pepstatin, leupeptin, and phenylmethylsulfonyl fluoride were products of Sigma.

Antibodies. Monoclonal antibodies RT97, BF10, 8D8, and 1215 were produced and kindly provided (as ascites fluids) by B. Anderton and colleagues, who showed that they stain the $M_{\mathrm{r}} 200,000$ and $M_{\mathrm{r}} 160,000$ neurofilament proteins as well as neurofibrillary tangles $(7,9)$. Monoclonal antibodies 147 and RS18, also provided as ascites fluids by Anderton and colleagues, stain neurofilaments but not tangles (9). Two monoclonal antibodies to the neurofilament $M_{\mathrm{r}} 200,000$ and $M_{\mathrm{r}} 160,000$ polypeptides (here designated BM200 and BM160, respectively) were obtained as purified IgG (20 $\mu \mathrm{g} / \mathrm{ml}$ ) from Boehringer Mannheim. SMI31 and SMI34 were purchased from Sternberger-Meyer (Jarrettsville, MD) as ascites fluids. The former is marketed as an antibody to phosphorylated neurofilament protein and the latter is marketed as an antibody to neurofilaments that stains Alzheimer neurofibrillary tangles. Polyclonal antibodies to PHF were obtained as reported (10). A monoclonal antibody to tau, 5E2, was raised in this laboratory and used as a hybridoma supernatant. A monoclonal antibody to MAP2, 5F9, that stains tangles has been reported (5) and was used as a supernatant. Affinity-purified antibodies specific to phosphorylated tau that were prepared from a PHF antiserum as described (14) were the gift of Y. Ihara.

Microtubule and Neurofilament Preparations. Microtubules were prepared from rat brains using the assembly/disassembly method of Shelanski et al. (19). Twice-cycled microtubules (12 $\mathrm{mg} / \mathrm{ml}$ in $0.1 \mathrm{M}$ morpholinoethanesulfonic acid buffer, $\mathrm{pH}$ 7.0, with $0.8 \mathrm{M} \mathrm{NaCl}$ and $0.5 \%$ mercaptoethanol) were boiled for 6 min and centrifuged at $60,000 \times g$ for $30 \mathrm{~min}$. The supernatant was used as the heat-stable MAP fraction. Neurofilaments were prepared from rat spinal cords as reported (6).

Dephosphorylation. Heat-stable MAP solution (0.3-0.5 $\mathrm{mg} / \mathrm{ml}$ ) was dialyzed to $0.1 \mathrm{M}$ Tris buffer ( $\mathrm{pH} 8$ ) and treated

Abbreviations: PHF, paired helical filament(s); MAP, microtubuleassociated protein.

*To whom reprint requests should be addressed. 
with $E$. coli alkaline phosphatase (type III-N), 10 units/ml, with protease inhibitors (leupeptin at $10 \mu \mathrm{g} / \mathrm{ml}$, pepstatin at 10 $\mu \mathrm{g} / \mathrm{ml}$, and $1 \mathrm{mM}$ phenylmethylsulfonyl fluoride) for $18 \mathrm{hr}$ at $37^{\circ} \mathrm{C}$.

Electrophoresis and Immunoblotting. Ten percent NaDod$\mathrm{SO}_{4} /$ polyacrylamide gel electrophoresis $\left(\mathrm{NaDodSO}_{4} /\right.$ PAGE) was performed according to Laemmli (20). Immunoblot studies were performed according to Towbin $e t$ al. (21). Blots were incubated with each antibody for $2 \mathrm{hr}$ at room temperature or overnight at $4^{\circ} \mathrm{C}$. Blots were stained by the avidin-biotin complex method (Vectastain ABC kit; Vector Laboratories, Burlingame, CA). The reactivities of monoclonal antibodies with phosphorylated and dephosphorylated forms of rat MAPs and rat neurofilament proteins (except for BF10, which was reacted with human neurofilaments) were determined according to Lee et al. (22) or by the method of Sternberger and Sternberger (23). Antibody dilutions are provided in the figure legends.

Tangle Reactivity. Tangle staining was determined by reactivity of the antibodies with in situ tangles in formalinfixed brain sections as well as with tangles isolated from frozen cerebral cortex in Tris/saline. All antibodies were used at the same dilutions as on immunoblots. Incubations in primary antibodies were for $2 \mathrm{hr}$ at room temperature or overnight at $4^{\circ} \mathrm{C}$, as used for the blots.

\section{RESULTS}

Immunoblots of heat-stable MAPs stained with each antibody are shown in Fig. 1. The tau proteins consist of six or seven bands in their phosphorylated form. When the MAP fraction was treated with alkaline phosphatase, a modest increase in electrophoretic mobility of tau proteins appeared, as reported by Lindwall and Cole (24). Antisera to PHF and the tau monoclonal antibody 5E2 stained phosphorylated and dephosphorylated forms of tau. Six different neurofilament monoclonal antibodies, 8D8, RT97, 1215, BF10, SMI31, and SMI34, all reacted with phosphorylated but not dephosphorylated tau proteins (Fig. 1). Similar results were obtained with affinity-purified antiphosphorylated tau antibodies prepared from a PHF antiserum (Fig. 1, lane 1). However, the staining intensity of each of the tau bands varied among the various antibodies examined. All of these antibodies stained neurofibrillary tangles (see, for example, Fig. 2). These antibodies also stained the gel excluded, insoluble material of heat-stable MAP fractions, suggesting that some portion of tau proteins is aggregated under the conditions of $\mathrm{NaDodSO}_{4} / \mathrm{PAGE}$ (Fig. 1). Neurofilament antibodies 1215 and SMI31 also reacted with MAP2; dephosphorylation abolished the reactivity with MAP2 of SMI31 but not of 1215 (Fig. 2). The other neurofilament antibodies tested (147, RS18, BM200, and BM160) did not react with any proteins in the heat-stable MAP preparation except for weak staining of a $M_{\mathrm{r}} 200,000$ band by 147 (Fig. 2). This band is sometimes weakly stained by other neurofilament antibodies and seems to be the neurofilament $M_{\mathrm{r}} 200,000$ polypeptide.

All neurofilament antibodies reacted with phosphorylated but not dephosphorylated neurofilament proteins, thus mimicking their reactivity on tau proteins (data not shown). An anti-MAP2, 5F9, reacted strongly with MAP2 and its degraded products, and dephosphorylation had no effect on this reaction (Fig. 1, lane 8). 5F9 seemed to stain bands in the tau region of the blot very weakly but we could not be certain that these were tau since, at higher dilutions, such staining was not seen and breakdown products of MAP2 in the $M_{\mathrm{r}}$ $50,000-60,000$ region could be the source of these reactive bands. The characterization of all antibodies is summarized in Table 1.

The effect of dephosphorylation on the staining of neurofibrillary tangles was determined using SMI31, RT97, and anti-PHF. Prior to dephosphorylation, all three antibodies
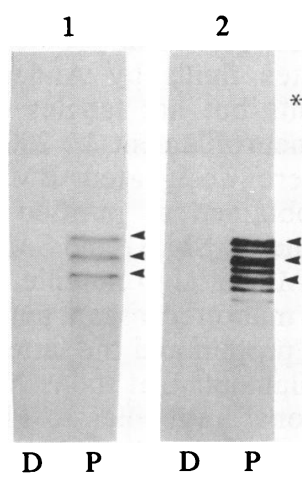

9

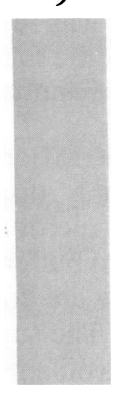

D P

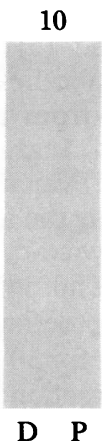

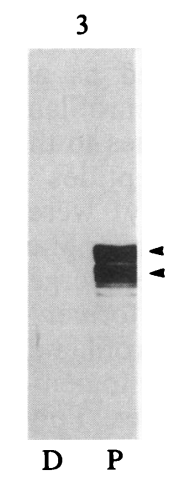

11

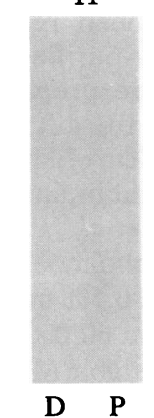

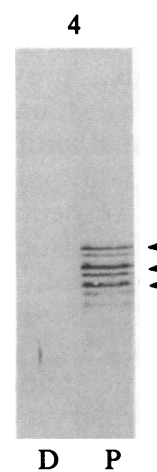

12
5
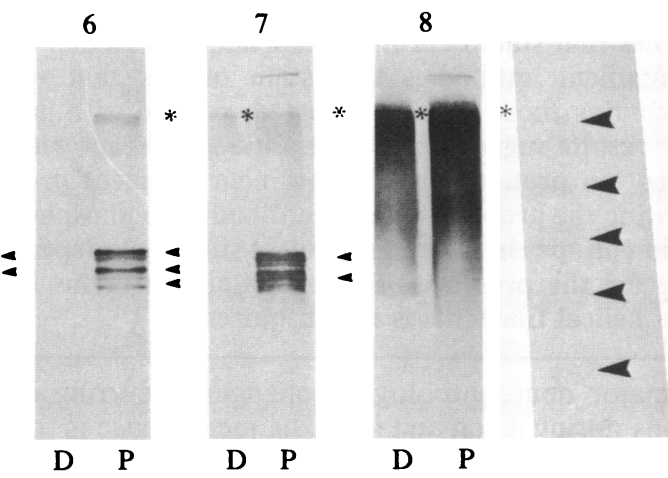

14

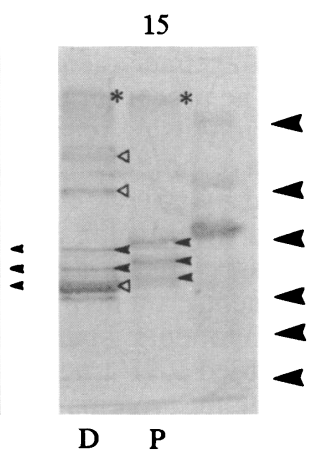

FIG. 1. Immunoblots of MAPs. MAPs on immunoblots of $10 \% \mathrm{NaDodSO}_{4} / \mathrm{PAGE}$ gels (D, MAPs dephosphorylated with alkaline phosphatase; P, MAPs without alkaline phosphatase treatment) were stained with affinity-purified, phosphorylated tau-specific antibodies from a PHF antiserum (1:5 dilution) (1), 8D8 (1:300) (2), RT97 (1:300) (3), BF10 (1:300) (4), SMI34 (1:300) (5), SMI31 (1:300) (6), 1215 (1:300) (7), 5 F9 (1:10) (8), 147 (1:300) (9), RS18 (1:300) (10), BM200 (1:100) (11), BM160 (1:20) (12), 5E2 (1:10) (13), and PHF antiserum (1:500) (14), amido black staining of blot (15). Molecular weight markers (shown as $\left.M_{\mathrm{r}} \times 10^{-3}\right): 200,97,68,43,(26$, lower figure), 18 . Arrowheads indicate tau proteins and asterisks indicate MAP2. Open arrowheads in (15) indicate bands derived from the alkaline phosphatase reagent. 
A

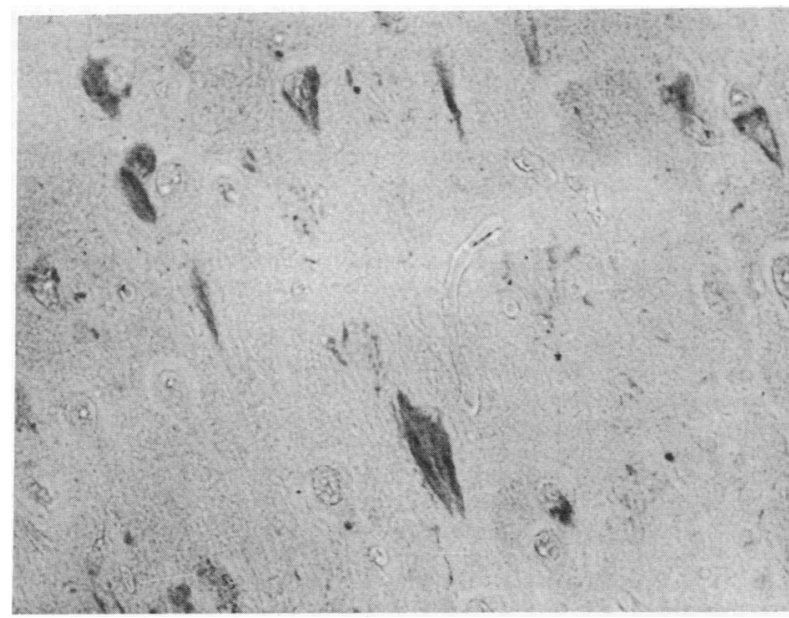

B

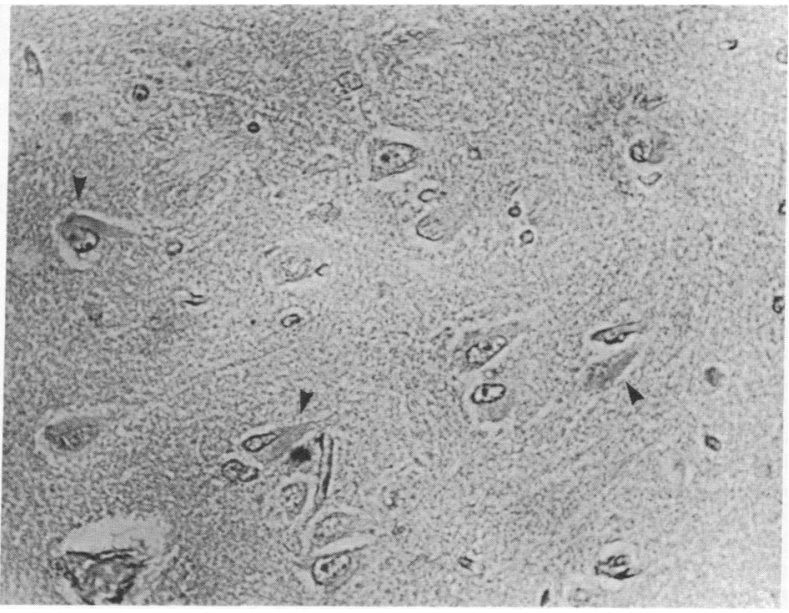

FIG. 2. Immunostaining of Alzheimer disease cortex with SMI31. $(A)$ Without alkaline phosphatase treatment, neurofibrillary tangles are stained. $(\times 340$.) $(B)$ After alkaline phosphatase treatment, unstained neurofibrillary tangles can be seen (arrowheads) and axons are also not stained. $(\times 210$. $)$ The antibody was diluted to 1:300, as used for the blots.

recognized tangles in Alzheimer disease brain sections, and RT97 and SMI31 also stained normal axons in the white matter, as reported. Alzheimer disease brain sections were incubated with alkaline phosphatase III-R ( 20 units $/ \mathrm{ml})$ and the protease inhibitors described above for $18 \mathrm{hr}$. Tangle and axonal staining by monoclonal neurofilament antibodies SMI31 (Fig. 2) and RT97 were markedly reduced or abolished by dephosphorylation. However, the staining of tangles by anti-PHF did not change under the same conditions.

\section{DISCUSSION}

Neurofilament Monoclonal Antibodies That Label PHF Crossreact with Tau Proteins. Our results can be summarized as follows. (i) All monoclonal neurofilament antibodies that stain Alzheimer neurofibrillary tangles that we examined react with tau and sometimes also react with MAP2 to varying degrees. (ii) All of these tangle-reactive antibodies react exclusively with the phosphorylated forms of the neurofilament and tau proteins. SMI31, an antibody to phosphorylated neurofilaments that was not previously reported to stain tangles, also reacted with tau. We, therefore, checked its reactivity on tangles and found that it, too, labeled tangles (Fig. 2). These results indicate that those neurofilament monoclonal antibodies that crossreact with phosphorylated epitopes of tau recognize neurofibrillary tangles. In further experiments, we have found that polyclonal anti-chicken neurofilament antibodies (25) and polyclonal anti-rat $M_{\mathrm{r}} 200,000$ neurofilament antibodies (6) that have been shown to stain tangles also react with phosphorylated and dephosphorylated tau. SMI32 and SMI33 (SternbergerMeyer) that react with phosphorylated and dephosphorylated neurofilament $M_{\mathrm{r}} 200,000$ protein do not label tangles or tau proteins (data not shown).

Our study suggests that neurofilament $M_{\mathrm{r}} 200,000$ and $M_{\mathrm{r}}$ 160,000 proteins, tau and MAP2, all have conformational or sequential similarities around phosphorylation sites and that these shared sites are recognized by the various neurofilament antibodies.

Altered Forms of Tau Are Present in PHF. Recently, we reported that polyclonal antibodies to PHF include antibodies to tau and, in particular, to phosphorylated tau (12-14). Antibodies to native tau also stain Alzheimer neurofibrillary tangles (13). In this study, we have shown that a monoclonal tau antibody, 5E2, that stains tangles recognizes phosphorylated and dephosphorylated tau. Similarly, polyclonal PHF antibodies that were raised against $\mathrm{NaDodSO}_{4}$-isolated $\mathrm{PHF}$

Table 1. Summary of reactivities of antibodies

\begin{tabular}{|c|c|c|c|c|c|c|c|}
\hline \multirow[b]{2}{*}{ Antibody } & \multirow[b]{2}{*}{ Tangle } & \multicolumn{2}{|c|}{ NF } & \multicolumn{2}{|c|}{ Tau } & \multicolumn{2}{|c|}{ MAP2 } \\
\hline & & $\mathbf{P}$ & Dep & $\mathbf{P}$ & Dep & $\mathbf{P}$ & Dep \\
\hline \multicolumn{8}{|l|}{ Monoclonal } \\
\hline \multicolumn{8}{|l|}{ NF } \\
\hline 8D8 & + & $+(\mathrm{H})$ & - & + & - & \pm & - \\
\hline RT97 & + & $+(\mathrm{H})$ & - & + & - & \pm & - \\
\hline 1215 & + & $+(\mathrm{H})$ & - & + & - & + & + \\
\hline BF10 & + & $+(M)$ & - & + & - & \pm & - \\
\hline SMI31 & + & $+(\mathrm{H})$ & - & + & - & + & - \\
\hline SMI34 & + & $+(\mathrm{H})$ & - & + & - & - & - \\
\hline 147 & - & $+(\mathbf{H})$ & - & - & - & - & - \\
\hline RS18 & - & $+(\mathrm{H})$ & - & - & - & - & - \\
\hline BM200 & - & $+(\mathrm{H})$ & - & - & - & - & - \\
\hline BM160 & - & $+(\mathbf{M})$ & - & - & - & - & - \\
\hline \multicolumn{8}{|l|}{ MAP2 } \\
\hline 5F9 & + & - & - & \pm & \pm & + & + \\
\hline \multicolumn{8}{|l|}{ Tau } \\
\hline $5 \mathrm{E} 2$ & + & - & - & + & + & - & - \\
\hline \multicolumn{8}{|c|}{ Rabbit polyclonal } \\
\hline Anti-PHF & + & - & - & + & + & \pm & \pm \\
\hline
\end{tabular}

P, phosphorylated form; Dep, dephosphorylated form; $H, M_{\mathrm{r}} 200,000$ rat neurofilament peptide; $M$, $M_{\mathrm{r}} 160,000$ rat neurofilament peptide. Tau and MAP2 were also prepared from rat. $\mathrm{H}$ or $\mathrm{M}$ shows mainly reacting component. 
also recognize phosphorylated and dephosphorylated tau. Indeed, all polyclonal and monoclonal tau antibodies tested to date on human neurofibrillary tangles show staining. These results suggest that the tau immunoreactivity found in PHF does not simply represent reactivity with phosphorylation sites but rather that phosphorylated and nonphosphorylated portions of tau are integrated into PHF. The reactivity of $\mathrm{NaDodSO}_{4}$-isolated neurofibrillary tangles with polyclonal tau antibodies (13) is consistent with this conclusion. Moreover, certain proteolytic fragments released from PHF by proteinase $\mathrm{K}$ digestion with $\mathrm{NaDodSO}_{4}$ treatment share epitopes with tau but are not recognized by neurofilament antibodies $(12,26)$. Thus, the tau proteins incorporated into PHF are partially resistant to proteinase $\mathrm{K}$ digestion. In contrast, normal tau protein is completely degraded by this enzyme. This partial resistance of the tau in PHF to protease digestion is probably due to conformational changes of tau in these pathological fibers. Further evidence for this view was reported using a monoclonal tau antibody, Tau-1, that stains neurofibrillary tangles $(15,16)$. Although the reactivity of Tau-1 with normal tau was not affected by dephosphorylation, its reactivity with tangles increased-i.e., many more tangles in Alzheimer brain sections were labeled by Tau-1 following alkaline phosphatase treatment. This differential effect of alkaline phosphatase suggests that tau in PHF contains different conformations and/or more phosphorylation sites than normal tau. Considering the resistance to protease digestion, we speculate that tau in PHF has altered conformations that allow tau to be more readily phosphorylated.

In view of the substantial evidence from several laboratories for a relationship between PHF and tau, it is possible to explain our present findings by postulating that tau proteins in PHF are recognized by monoclonal neurofilament antibodies. It was reported by Miller et al. that the double staining of PHF by anti-PHF and 8D8 showed some competition (9). In view of our findings, this result can now be interpreted to suggest that the same tau antigens in the PHF were recognized by these two kinds of antibodies rather than that the two different antigens (tau and neurofilament) are distributed together in PHF. Some neurofilament antibodies examined here react with MAP2 and tau. MAP2 immunoreactivities are known to exist in neurofibrillary tangles $(4,5)$. Thus, we cannot exclude the possibility that the staining of PHF with certain monoclonal neurofilament antibodies is partly due to their anti-MAP2 activity.

Variation in the Immunoreactivity of Individual Tau Proteins May Depend on Conformational Differences. In this study, we used some antibodies at higher concentrations $(1: 300)$ than usually employed $(1: 1000 \rightarrow 1: 10,000)$, and the degree of reactivity with normal tau on electrophoretic transfer blots seemed not to correlate closely with that of tangles in tissue sections. Also, the staining of the neurofilament proteins on blots by the neurofilament antibodies appeared to be greater than the staining of the tau proteins. The affinity of antibodies might differ between tau proteins on blots and tau proteins within PHF, in which tau may have an altered conformation. In this regard, the heterogeneous staining of the multiple tau polypeptides by the antibodies we used is important. Since a single phosphate incorporation into tau is supposed to produce a shift in electrophoretic mobility on $\mathrm{NaDodSO}_{4} / \mathrm{PAGE}_{\text {gels }}$ (24), a single phosphate incorporation might also change the immunoreactivities of these antibodies. Tau polypeptides are thought to have approximately three phosphorylated sites $(24,27)$. Thus, any one phosphorylated site is recognized by several monoclonal antibodies. However, these antibodies stain each of the six or seven tau bands with varying intensities, suggesting that these antibodies recognize slightly different epitopes around the phosphorylated sites. Although several monoclonal an- tibodies may recognize the same site in each tau form, some forms are strongly stained and others are barely stained; for example, lower molecular weight forms are barely stained by RT97, SMI34 and 1215. Presumed conformational changes of tau in PHF could further alter the affinity of the antibodies, since even in the heterogeneous forms of normal tau there are different affinities. Such conformational considerations could also explain the previous report that monoclonal neurofilament antibodies hardly stained fresh $\mathrm{NaDodSO}_{4}$ extracted tangles but that reactivity reappeared after prolonged incubation of tangles in $\mathrm{NaDodSO}_{4}(28,29)$. Interestingly, we observed that neurofilament monoclonal antibody 1215 stained tau weakly after a 2-hr incubation of the blot at room temperature but stained it strongly after overnight incubation at $4^{\circ} \mathrm{C}$, compared with its unchanged staining of MAP2 on the same blot (data not shown). Thus, the accessibility of antibodies to sites on normal tau also changes under various conditions.

Further Evidence for the Presence of Distinct Neurofilament Components in PHF Is Now Required. The binding of several neurofilament antibodies to the PHF has been confirmed even at the electron microscopic level. At present, however, we have no independent evidence for the existence of neurofilament components in PHF. To propose this possibility, it must now be demonstrated that PHF contain amino acid sequences or specific immunoreactive sites (other than phosphorylated epitopes) deriving solely from neurofilaments. In the light of the data reported here, the notion of an aberrant phosphorylation of neurofilaments in Alzheimer disease (17) requires reconsideration. Our report may clarify somewhat the controversy about the nature of the principal antigenic components of PHF. Every antibody that was previously reported to react with PHF [antibodies to PHF (11-13), antibodies to microtubule fractions (30), and antibodies to neurofilament proteins] recognizes tau. Phosphorylated epitopes on several cytoskeletal proteins thus seem to crossreact (31). These results indicate the need for caution when using antibodies to decipher the composition of abnormal cytoskeletal proteins.

Note. Ksiezak-Reding et al. (32) have also reported on Alzheimer disease neurofibrillary tangles.

We are very grateful to Drs. B. Anderton and Y. Ihara for providing their antibodies. The work was supported by Grants NS 23340 and AG 06173 from the National Institutes of Health. D.J.S. is a recipient of a Metropolitan Life Foundation Award for the study of Alzheimer disease.

1. Kidd, M. (1963) Nature (London) 197, 192-193.

2. Grundke-Iqbal, K., Johnson, A. B., Wisniewski, H. M., Terry, R. D. \& Iqbal, K. (1979) Lancet i, 578-580.

3. Yen, S.-H., Gaskin, F. \& Terry, R. D. (1981) Am. J. Pathol. 104, 77-89.

4. Nukina, N. \& Ihara, Y. (1983) Proc. Jpn. Acad. 59B, 284-287.

5. Kosik, K. S., Duffy, L. K., Dowling, M. M., Abraham, C., McCluskey, A. \& Selkoe, D. J. (1984) Proc. Natl. Acad. Sci. USA 81, 7941-7945.

6. Ihara, Y., Nukina, N., Sugita H. \& Toyokura, T. (1981) Proc. Jpn. Acad. 57B, 152-156.

7. Anderton, B. H., Breinburg, D., Downes, M. J., Green, P. J., Tomlinson, B. E., Ulrich, J., Wood, J. N. \& Kahn, J. (1982) Nature (London) 298, 84-86.

8. Perry, G., Rizzuito, N., Autilio-Gambetti, L. \& Gambetti, P. (1985) Proc. Natl. Acad. Sci. USA 82, 3916-3920.

9. Miller, C. J., Brion, J.-P., Calvert, R., Chin, T. K., Eagles, P. A. M., Downes, M. J., Flament-Durand, J., Haugh, M.; Kahn, J., Probst, A., Ulrich, J. \& Anderton, B. H. (1986) EMBO. J. 5, 269-279.

10. Ihara, Y., Abraham, C. \& Selkoe, D. J. (1983) Nature (London) 304, 727-730.

11. Brion, J. P., van den Bosch de Aguilar, P., Flament-Durand, J. (1985) in Advances in Applied Neurological Science: Senile 
Dementia of the Alzheimer Type, eds. Traber, J. \& Gispens, W. H. (Springer, Berlin), pp. 164-174.

12. Nukina, N. \& Ihara, Y. (1986) J. Biochem. (Tokyo) 99, 15411544.

13. Kosik, K. S., Joachim, C. L. \& Selkoe, D. J. (1986) Proc. Natl. Acad. Sci. USA 83, 4044-4048.

14. Ihara, Y., Nukina, N., Miura, R. \& Ogawara, M. (1986) J. Biochem. (Tokyo) 99, 1807-1810.

15. Wood, J. G., Mirra, S. S., Pollock, N. J. \& Binder, L. I. (1986) Proc. Natl. Acad. Sci. USA 83, 4040-4043.

16. Grundke-Iqbal, I., Iqbal, K., Tung, Y.-C., Quinlan, W., Wisniewski, H. M. \& Binder, L. I. (1986) Proc. Natl. Acad. Sci. USA 83, 4913-4917.

17. Sternberger, N. H., Sternberger, L. A. \& Ulrich, J. (1985) Proc. Natl. Acad. Sci. USA 82, 4274-4276.

18. Cork, L. C., Sternberger, N. H., Sternberger, L. A., Casanova, M. F., Struble, R. G. \& Price, D. L. (1986) J. Neuropathol. Exp. Neurol. 45, 56-64.

19. Shelanski, M. L., Gaskin, F. \& Cantor, C. R. (1973) Proc. Natl. Acad. Sci. USA 70, 765-768.

20. Laemmli, U. K. (1970) Nature (London) 227, 680-685.

21. Towbin, H., Staehelin, T. \& Gordon, J. (1979) Proc. Natl. Acad. Sci. USA 76, 4350-4354.
22. Lee, V. M.-T., Carden, M. J. \& Trojanowski, J. Q. (1986) J. Neurosci. 6, 850-858.

23. Sternberger, L. A. \& Sternberger, N. H. (1983) Proc. Natl. Acad. Sci. USA 80, 6126-6130.

24. Lindwall, G. \& Cole, R. D. (1984) J. Biol. Chem. 259, 53015305.

25. Dahl, D., Selkoe, D. J., Pero, R. T. \& Bignami, A. (1982) J. Neurosci. 2, 113-119.

26. Nukina, N. \& Ihara, Y. (1985) J. Biochem. (Tokyo) 98, 1715-1718.

27. Selden, S. C. \& Pollard, T. D. (1983) J. Biol. Chem. 258, 7064-7071.

28. Rasool, C. G., Abraham, C., Anderton, B. H., Haugh, M., Kahn, J. \& Selkoe, D. J. (1984) Brain Res. 310, 249-260.

29. Rasool, C. G. \& Selkoe, D. J. (1984) Brain Res. 322, 194-198.

30. Grundke-Iqbal, I., Iqbal, K., Quinlan, M., Tung, Y.-C., Zaidi, M. A. \& Wisniewski, H. M. (1986) J. Biol. Chem. 261, 60846088.

31. Luca, F. C., Bloom, G. S. \& Vallee, R. B. (1986) Proc. Natl. Acad. Sci. USA 83, 1006-1010.

32. Ksiezak-Reding, H., Dickson, D. W., Davies, P. \& Yen, S.-H. (1987) Proc. Natl. Acad. Sci. USA 84, 3410-3414. 